\title{
Wettability Studies Using Zeta Potential Measurements
}

\author{
Ghada Bassioni $^{1}$ and Syed Taha Taqvi ${ }^{2}$ \\ ${ }^{1}$ Chemistry Department, Faculty of Engineering, Ain Shams University, P.O. Box 11517, Cairo, Egypt \\ ${ }^{2}$ Department of Chemical Engineering, The Petroleum Institute, P.O. Box 2533, Abu Dhabi, UAE \\ Correspondence should be addressed to Ghada Bassioni; ghada_bassioni@eng.asu.edu.eg
}

Received 10 December 2014; Accepted 11 February 2015

Academic Editor: Tomokazu Yoshimura

Copyright (C) 2015 G. Bassioni and S. Taha Taqvi. This is an open access article distributed under the Creative Commons Attribution License, which permits unrestricted use, distribution, and reproduction in any medium, provided the original work is properly cited.

\begin{abstract}
Wettability studies have been carried out on reservoir rocks using different techniques such as the Amott-Harvey method, the USBM method, and the contact angle method, all with limitations. In this study, the wettability is studied by discussing the surface charge using zeta potential measurements. The study relies on the finding that carbonated reservoir rocks, consisting of CaCO${ }_{3}$ mainly, are positively charged and their surface has the potential to adsorb significant quantities of anions. Moreover, heavy fractions such as asphaltenes are reported to remain afloat depending on dispersive forces present in the oil and its various fractions. Experiments are carried out on aqueous limestone suspension with the addition of crude oil. The experiment is repeated with the use of polymeric inhibitors, A and B. The zeta potential is found to alter depending on the sequence of polymeric inhibitor in oil/water addition. The inhibitor is found to adsorb on the limestone surface, with a net negative charge, causing repulsion between crude oil and the inhibitor and, hence, preventing the deposition of heavy fractions and particularly asphaltenes. This study gives a comprehensive insight on the mechanism of polymeric inhibitor interaction with the surface and the effect of wettability on its performance.
\end{abstract}

\section{Introduction}

Oil has been a major source of energy for ages. Nevertheless, heavy fractions of crude oil, especially asphaltenes, have been an area of concern since then. Asphaltenes are the most polar petroleum macromolecules [1]. Moreover, asphaltenes, retaining their unique ambiguous identity, tend to coagulate and are held responsible for many phenomena in the petroleum industry such as well bore plugging and pipeline deposition, stabilization of water/oil emulsions, sedimentation and plugging during crude oil storage, adsorption on refining equipment, and coke formation [1]. A main characteristic to be considered, while analyzing such problems, is the wettability of reservoir rock. Several researchers over the past seventy years have been studying the wettability effect on oil production and recovery [2]. However, all the current wettability measuring techniques present in the industry lack in providing much information regarding the wettability alteration in situ on a microscopic level $[3,4]$.

The aim of this study is to carry out a wettability study using zeta potential measurements in order to obtain a wettability profile of reservoir rock, focusing on the wettability transition region. In addition, the study will focus on studying the inhibition mechanism of inhibitors to demonstrate the application of the proposed zeta potential method. The significance of this study is a novel wettability measuring technique using the zeta potential approach that studies wettability on a microscopic level. Furthermore, as a practical application, it allows examination of flow assurance inhibitors for compatibility with reservoir rock and fluids before injection.

Wettability is defined as the tendency of one fluid to spread on or adhere to a solid surface in the presence of other immiscible fluids [5]. Talking from the view of a solid, it can be defined as the relative preference of a solid surface to be coated by a certain fluid in a system [3]. Additionally, it is the measure of the degree of contact between two immiscible fluids and a solid surface, resulting from the mutual intermolecular interactions between the fluids and the solid [6].

An important rock property that controls location, saturation distribution, and flow behavior of reservoir fluids is wettability. As a result, it affects several petrophysical properties such as capillary pressure, relative permeability, waterflood behavior, electrical properties, and enhanced oil recovery (EOR) [6]. 
Statistically speaking, about $50 \%$ of the world's proven oil reserves are contained in carbonate reservoirs [7]. Furthermore, most reservoirs located in the Gulf are mainly composed of limestone (i.e., calcium carbonate). Carbonate rocks are generally hydrophobic; if subjected to choice of oil or water, they will prefer oil and become oil-wet [8]. Initially, carbonate rocks are of strong water-wet character. In order to adsorb to a substrate, an incoming surfactant may need to displace water of hydration at the solid surface [9]. Therefore, during oil migration, oil replaces water by buoyancy, followed by thin oil column and an oil/water interface [8]. Experimental evidences suggest that carbonate particles usually adsorb organic coating which protects them from dissolution in the slightly acidic water formations. The complex surface chemistry of calcium carbonate is generally generated in aqueous media caused by the dissolution of ions from the $\mathrm{CaCO}_{3}$ surface [10]. The partial dissolution of calcium carbonate affects its surface charge, its colloidal properties, and its interaction with salts.

Apart from that, carbonate reservoirs are well known for their low productivity and thus they are very good candidates for enhanced oil recovery (EOR). In petroleum fluids, the heavy fractions of the polydisperse asphaltenic compounds have been observed to exist in the form of micelles or colloidal suspensions [1]. This suspension is assumed to be caused by resins (heavy and mostly aromatic molecules) which are adsorbed to the surface of asphaltene, keeping them afloat because of repulsive forces between the resin molecules in the solution and the adsorbed resins on the macromolecular (asphaltene) surface [1]. It has been observed that heavy fractions of these petroleum fluids such as asphaltene deposit when reservoir conditions are altered. On the other hand, it was found in a study that $\mathrm{CaCO}_{3}$ has the potential to adsorb significant quantities of anions due to its positive surface charge [10]. Thus, alkaline substances and cationic surfactants are added to improve the recovery factor. They achieve this by a combination of decreased interfacial tension between oil and water and supply of negative charges onto rock surfaces that favor the repulsion of adsorbed materials by switching the equilibrium of surface charges [6].

Among the techniques used for studying wettability, the Amott-Harvey method and the United States Bureau of Mines (USBM) method are the most commonly used industrial methods for characterizing wettability of oil/brine/rock systems [4]. However, these methods have no validity as an absolute measurement tool but are an industry standard for comparing the wettability of various core plugs. Contact angle testing method is also used to measure the wettability of a mineral surface in contact with fluid from the reservoir. However, this method consists of a set of limitations that include its inability to take into account the heterogeneity of the rock surface [3]. Moreover, it is found that a liquid drop on a surface can have many different stable contact angles and there are reproducibility issues with the experiment. Rise in Core (RIC) method was introduced that employed the Washburn equation for dynamic determination of contact angle [3]. However, further studies need to be conducted in order to verify it.
In an experiment conducted in a study, zeta potential measurements are used to determine the surface charge of the calcium carbonate particles in the presence of varying dosages of the adsorbates [10]. And, later it is concluded that $\mathrm{CaCO}_{3}$ has the potential to adsorb significant quantities of anions due to its positive charge. The amount of ions, adsorbed, is further quantified by total organic carbon (TOC) measurements which lie in good accordance with zeta potential measurements and reflect the adsorption potential of $\mathrm{CaCO}_{3}$ [10]. This approach can be used for wettability studies.

\section{Materials and Methods}

Several experiments are conducted to study wettability on reservoir rocks using zeta potential measurements:

(1) wettability study on limestone-water mixture with addition of crude oil to obtain the wettability profile of limestone, focusing on the transition region,

(2) wettability study on limestone-crude oil mixture with addition of water to observe the effect of water injection on oil-wet limestone,

(3) wettability study on limestone-water mixture with addition of crude oil in presence of inhibitors to demonstrate the practical application of the zeta potential approach and to get a better understanding of the inhibition mechanism the inhibitors follow.

Crude oil samples used in the experiment were taken from the Middle East with properties that were on the average. $\mathrm{CaCO}_{3}$, with similar mineralogy to that of actual reservoir rock, is used to perform the wettability experiments. This sample " $\mathrm{CaCO}_{3}$ " was acquired from within the region to which the crude oil belongs. Inhibitor solutions are used in the industry for flow assurance purposes. From a variety of polymeric inhibitors, $\mathrm{A}$ and $\mathrm{B}$ are chosen based on their ability of inhibition with one being much stronger than the other. A laser granulometer is used to determine the particle size of the $\mathrm{CaCO}_{3}$ particles. The particle size needs to be reported in order to determine the zeta potential, based on the electroacoustic measurement. Zeta potential measurements are carried out using the Model DT-300 Zeta Potential probe (Dispersion Technology, Inc., New York, USA) where the readings are recorded on the computer. The zeta probe, comprising a central gold electrode and surrounding steel cylinder, measures the zeta potential with the use of an electroacoustic sensor. The piezo-crystal inside the probe generates a sound pulse that propagates through the sample via the gold electrode. The ultrasound moves the particle relative to the liquid, which displaces double layers and generates an electric field. As a result, the field changes the electric potential. Whilst the electric potential of the steel cylinder remains zero, the device measures the current flowing between the gold and steel. By further calculation, it calculates the zeta potential.

In this setup, the probe is placed in an external cell, along with the mixture. An electronic stirrer continuously stirs with 


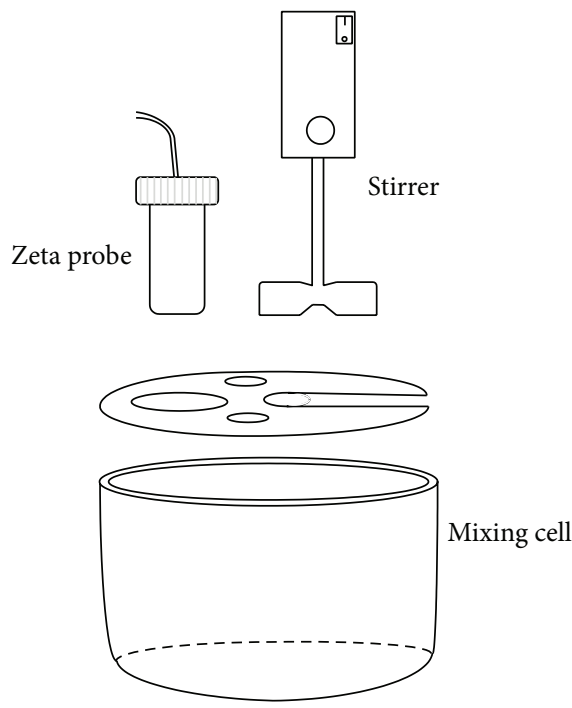

FIGURE 1: Schematic diagram of the apparatus used in the zeta potential technique to measure wettability.

mixture whilst the zeta potential measurements are made, as seen in Figure 1.

Particle charge detection (PCD) analysis is carried out separately on the set of polymeric inhibitors using Mütek PCD-04 Particle Charger Detector. This was carried out in order to study the possible effect each will have on the limestone suspensions, particularly the adsorption tendency of these inhibitors on $\mathrm{CaCO}_{3}$. Experiments conducted in this study are carried out using distilled water since wettability effects become very important when brine saturation is lowered [11].

2.1. Limestone-Water Mixture. The limestone-water suspensions consist of $200 \mathrm{~g}$ of limestone poured into $200 \mathrm{~g}$ of water over a period of 1 minute. The slurry is allowed to sit for 1 minute. After that, the contents of the beaker are vigorously stirred for 2 minutes in a beaker with a spoon. The suspension is transferred to a mixing cell for studying the wettability. Measurements of the zeta potential are recorded for the limestone slurry. Afterwards, crude oil is added milliliterwise to the mixture and the zeta potential is measured after each addition.

2.2. Limestone-Crude Oil Mixture. For the limestone-crude oil mixture, $200 \mathrm{~g}$ of limestone is added to $200 \mathrm{~g}$ of crude oil, within 1 minute. The mixture is allowed to sit for 1 minute. After that, the slurry is stirred vigorously for 2 minutes. Measurements of the zeta potential are recorded for the limestone slurry. Afterwards, distilled water is added milliliter-wise to the mixture and the zeta potential is measured after each addition.

2.3. Limestone-Water Mixture with Inhibitor A. An aqueous limestone suspension is prepared with the addition of polymeric inhibitor A. A moisture analyzer is used to determine the water content in the inhibitor solution. In order to keep

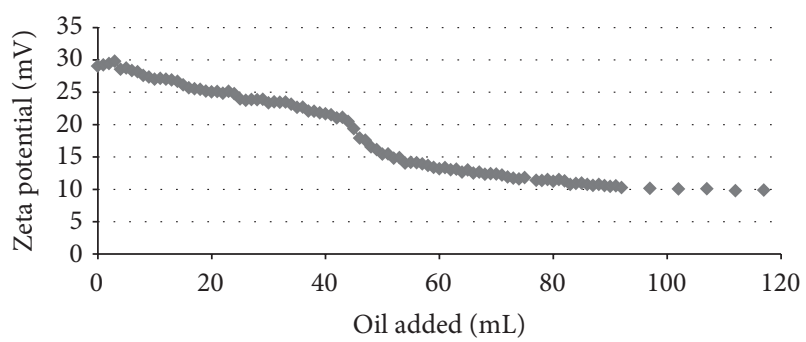

FIGURE 2: Zeta potential measurements for aqueous limestone suspension with volume of crude oil added.

the total water content of the mixture constant (i.e., $200 \mathrm{~g}$ ), calculations were made to account the total inhibitor solution to be added to the limestone mixture. For inhibitor $\mathrm{A}$, the moisture content is found to be $96.2 \%$. Therefore, $10.4 \mathrm{~g}$ of inhibitor solution is added to $189.6 \mathrm{~g}$ of water, in a beaker. $200 \mathrm{~g}$ of limestone is added to the mixture, within 1 minute. The target amount of inhibitor is $0.2 \mathrm{wt} \%$. The contents of the beaker are allowed to sit for 1 minute. Next, the mixture is stirred vigorously for 2 minutes. The zeta potential is measured for the mixture without any oil added. Readings of zeta potential are taken after every $\mathrm{mL}$ of crude oil added.

2.4. Limestone-Water Mixture with Inhibitor B. For polymeric inhibitor $\mathrm{B}$, the moisture content is found to be $71.3 \%$. Thus, the aqueous limestone suspension is prepared using $1.40 \mathrm{~g}$ of inhibitor solution, $198.6 \mathrm{~g}$ of water, and $200 \mathrm{~g}$ of limestone, in a beaker. The limestone is added to the mixture, within a minute. The target amount of inhibitor is $0.2 \mathrm{wt} \%$. The contents of the beaker are allowed to sit for 1 minute. Next, the mixture is stirred vigorously for 2 minutes. Zeta potential is measured for the mixture without any oil added. Readings of zeta potential are taken after every $\mathrm{mL}$ of crude oil added.

\section{Results and Discussion}

The size of the limestone particle is found to be $7.06 \pm$ $0.211 \mu \mathrm{m}$. On the other hand, the PCD analysis showed that both polymeric inhibitors, $\mathrm{A}$ and $\mathrm{B}$, used have a surface charge of $-2097 \mathrm{mV}$ and $-1145 \mathrm{mV}$, respectively.

3.1. Limestone-Water Mixture. Figure 2 shows the changes in wettability profile of the limestone-water suspension as crude oil is added.

The zeta potential at $0 \mathrm{~mL}$ of oil added, indicating the surface charge for aqueous limestone suspension, is found to be $+29 \mathrm{mV}$. At this stage, limestone is completely waterwet. As seen from Figure 2, the surface charge of the aqueous limestone suspension gradually falls upon addition of crude oil. The fall of the zeta potential value is steady until about $40 \mathrm{~mL}$ of crude oil is added. Between the region of $40 \mathrm{~mL}$ and $45 \mathrm{~mL}$, the system experiences a decrease in value with a relatively higher slope. This region demonstrates the transition of the limestone character from water-wet to oilwet. Initially, upon the addition of crude oil, the system remains stable, keeping the oil in bulk. At the transition 


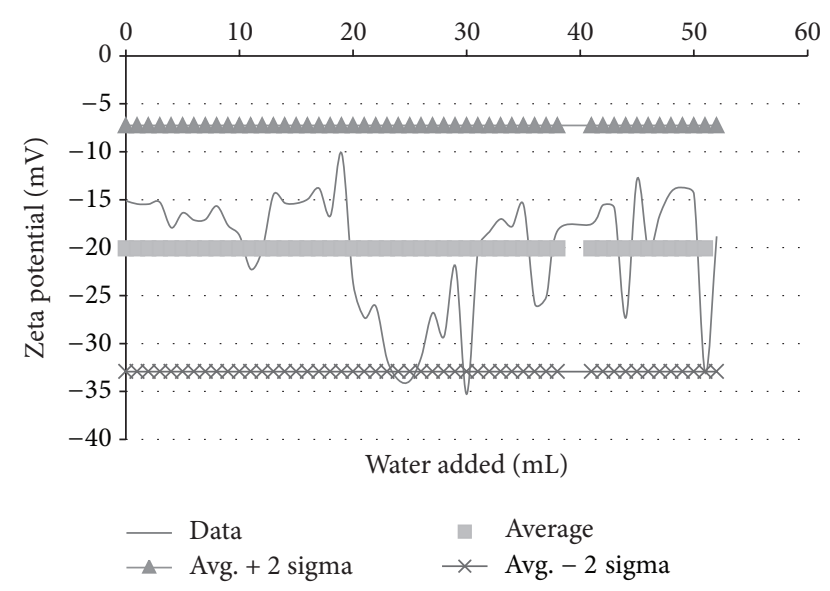

FIGURE 3: Zeta potential measurements for limestone-oil suspension with volume of water added.

stage, the limestone can be seen coated with oil molecules, displacing the water into the bulk. The system resumes to a gradual decrease in the zeta potential value until a plateau is reached. At this point, the limestone can be regarded as completely oil-wet with almost negligible change in the zeta potential upon further addition of crude oil.

3.2. Limestone-Crude Oil Mixture. Figure 3 shows the changes in zeta potential of the limestone-crude oil mixture as water is added.

The initial zeta potential of the limestone-oil suspension is found to be $-15 \mathrm{mV}$. This proves that oil carries a high negative charge, as compared to the limestone, lowering the surface charge of the limestone suspension to a negative value. Figure 3 shows that, upon addition of water, the zeta potential fluctuates around the average value. This phenomenon can be explained on a molecular level.

Oil molecules, mainly resins, are adsorbed onto the surface by electrostatic forces due to their high polarity [12, 13]. When water is added, it washes away the resins from the calcium carbonate surface. Since the electrostatic attraction between the two still exists, the molecules tend to readily adsorb back onto the surface, over time. This continuous adsorption of the resin molecules and the washing of the surface cause the oscillations, as in Figure 3. Figure 4, showing the remainder of the experiment, helps us to understand this behavior further.

The experiment is stopped after $53 \mathrm{~mL}$ of water added. As seen in Figure 4, deposition of heavy fractions of oil on the limestone surface occurs, forming large chunks of solid matter. Resins are assumed to be responsible for keeping the heavy fractions of oil afloat by repulsive forces. When they adsorb onto the limestone surface, the heavy fractions of oil deposit and changes in the composition occur, hence destabilizing the limestone-oil suspension.

3.3. Limestone-Water Mixture with Inhibitors. The experiment is carried out on the aqueous limestone suspension with

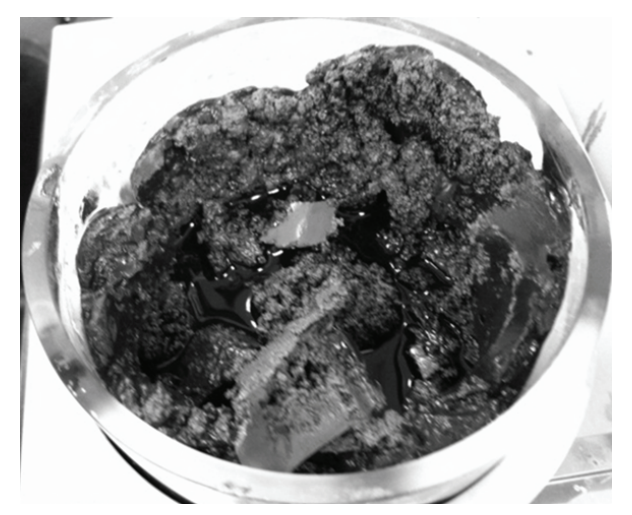

FIgURE 4: Limestone-oil suspension upon addition of $53 \mathrm{~mL}$ of water.

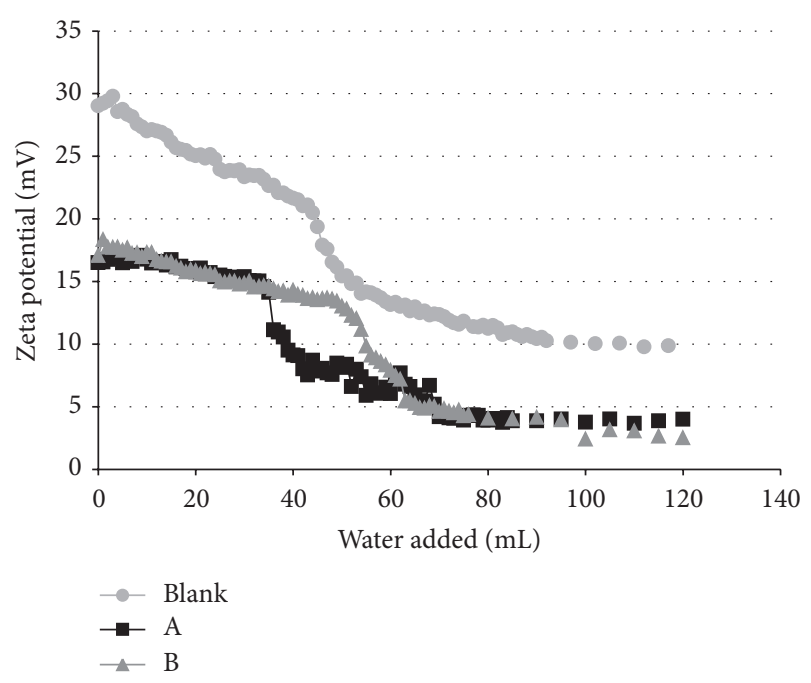

FIGURE 5: Zeta potential measurements of aqueous limestone suspension with and without polymeric inhibitors, A and B.

polymeric inhibitors and the data is compared to the blank sample. Figure 5 shows the set of data obtained.

It can be seen that both the indicators reduce the zeta potential to almost a similar value of $16 \mathrm{mV}$ even though they differ greatly in terms of their surface charge. Moreover, both inhibitors experience almost an equal fall in the zeta potential after $80 \mathrm{~mL}$ of crude oil added. However, inhibitor A experiences an earlier fall relative to inhibitor B. Such data can provide information regarding the inhibition capability of a certain inhibitor in a particular reservoir. Moreover, in favor of production in a water-wet reservoir, the use of inhibitors would prevent the oil-wet state to some extent.

It can be observed that the aqueous limestone suspension undergoes a dual effect with the inhibitor. The zeta potential decreases with the addition of crude oil to the inhibitor. This behavior can be explained using Figure 6 .

Since limestone is positively charged, the highly negatively charged inhibitor gets attracted and adsorbs onto the surface of limestone. The inhibitor possesses a higher negative charge than the crude oil; thus it remains adsorbed on the limestone surface, keeping the oil particles in the bulk. The 

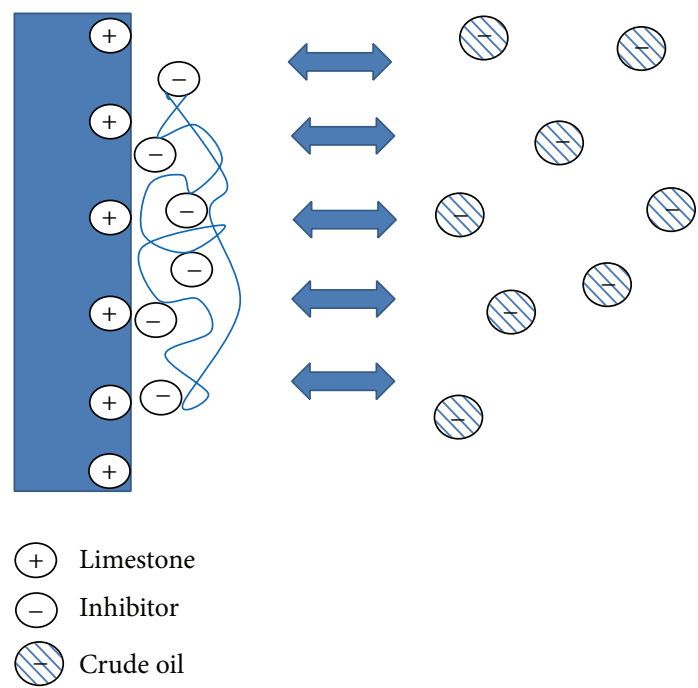

FIGURE 6: Mechanism of inhibitor adsorbing on the limestone surface in the presence of crude oil.

aqueous inhibitor-wet surface charge is negative and the zeta potential of the suspension falls to an even lower value upon addition of crude oil due to its negative charge.

Due to the negative charges present on both species, crude oil and aqueous inhibitor, there exist forces of repulsion, preventing the crude oil particles from coming in contact with the limestone surface and keeping them afloat in the oil. This prevents the deposition of heavy fractions of oil, maintaining the composition of the crude oil.

\section{Conclusion}

This study gives a better understanding of the wettability of reservoir rocks using zeta potential measurements. The behavior of the rock can be seen at different stages of oil concentration. Moreover, the mechanism of the polymeric inhibitor interaction with the surface can be clearly seen.

Unlike the industrial and proposed methods available, zeta potential neither is an absolute value nor has any certain measurement limitations. It does not require tedious experiments to be conducted. Complete wettability profiles can be obtained through a single experiment. Additionally, heterogeneity of rock surface can be accounted for using the zeta potential technique. Conducting such experiments is a simple way to study the behavior of each inhibitor and its effectiveness, for different reservoirs in regions around the globe. In addition, the experiments are simple to perform and data obtained can be analyzed with ease.

Further studies can be carried out, varying parameters like temperature since the water wetness of carbonate reservoirs increases as the temperature increases [14].

\section{Conflict of Interests}

The authors declare that there is no conflict of interests regarding the publication of this paper.

\section{Acknowledgments}

The authors would like to acknowledge Nicy Kallely and Muhammad Jaffar for conducting the PCD analysis and assisting in the zeta potential experiments.

\section{References}

[1] R. Z. Syunyaev, R. M. Balabin, I. S. Akhatov, and J. O. Safieva, "Adsorption of petroleum asphaltenes onto reservoir rock sands studied by near-infrared (NIR) spectroscopy," Energy and Fuels, vol. 23, no. 3, pp. 1230-1236, 2009.

[2] M. Faerstein, P. Couto, and J. L. D. Alves, "A comprehensive approach for assessing the impacts of wettability on oil production in carbonate reservoirs," in Proceedings of the SPE Reservoir Characterisation and Simulation Conference and Exhibition (RCSC '11), pp. 777-795, October 2011.

[3] S. Ghedan, C. H. Canbaz, D. Boyd, G. Mani, and M. Haggag, "Wettability profile of a thick carbonate reservoir by the new rise in core wettability characterization method," in Proceedings of the 14th Abu Dhabi International Petroleum Exhibition and Conference (ADIPEC '10), pp. 2203-2217, Abu Dhabi, UAE, November 2010.

[4] S. M. Ma, X. Zhang, N. R. Morrow, and X. Zhou, "Characterization of wettability from spontaneous imbibition measurements," Journal of Canadian Petroleum Technology, vol. 38, pp. $1-8,1999$.

[5] S. T. Kim, M. E. Boudh-Hir, and G. A. Mansoori, "The role of asphaltene in wettability reversal," in Proceedings of the 65th Annual Technical Conference and Exhibition of the Society of Petroleum Engineers, New Orleans, La, USA, 1990.

[6] P. Macini, V. Bortolotti, and F. Srisuriyachai, "Wettability index of carbonatic reservoirs and EOR: laboratory study to optimize alkali and surfactant flooding," in Proceedings of the SPE International Oil \& Gas Conference Exhibition, SPE Paper 131043, Beijing, China, June 2010.

[7] T. M. Okasha, J. J. Funk, and H. N. Al-Rashidi, in Proceedings of the 15th SPE Middle East Oil \& Gas Show and Conference, 2007.

[8] I. Marzouk, H. Takezaki, and M. Miwa, "Geologic controls on wettability of carbonate reservoirs, Abu Dhabi, U.A.E”, in Proceedings of the SPE Middle East Oil Show, Manama, Bahrain, March 1995.

[9] R. Atkin, V. S. J. Craig, E. J. Wanless, and S. Biggs, "Mechanism of cationic surfactant adsorption at the solid-aqueous interface," Advances in Colloid and Interface Science, vol. 103, no. 3, pp. 219304, 2003.

[10] G. Bassioni, "Mechanistic aspects on the influence of inorganic anion adsorption on oilfield scale inhibition by citrate," Journal of Petroleum Science and Engineering, vol. 70, no. 3-4, pp. 298301, 2010.

[11] W. G. Anderson, "Wettability literature survey-part 3: the effects of wettability on the electrical properties of porous media," Journal of Petroleum Technology, vol. 38, pp. 1371-1378, 1986.

[12] G. Bassioni, F. Abdulla, Z. Morsy, and N. El-Faramawy, "Evaluation of naturally occurring radioactive materials (NORM) in inorganic and organic oilfield scales from the Middle East," Archives of Environmental Contamination and Toxicology, vol. 62, pp. 361-368, 2012.

[13] S. T. Taqvi, A. Almansoori, and G. Bassioni, "Modeling the impact of wettability alterations on calcium carbonate system 
for crude oil and asphaltenic solutions," Industrial and Engineering Chemistry Research, vol. 53, no. 12, pp. 4773-4777, 2014.

[14] D. N. Rao, "Wettability effects in thermal recovery operations," SPE Reservoir Evaluation and Engineering, vol. 2, no. 5, pp. 420430, 1999. 

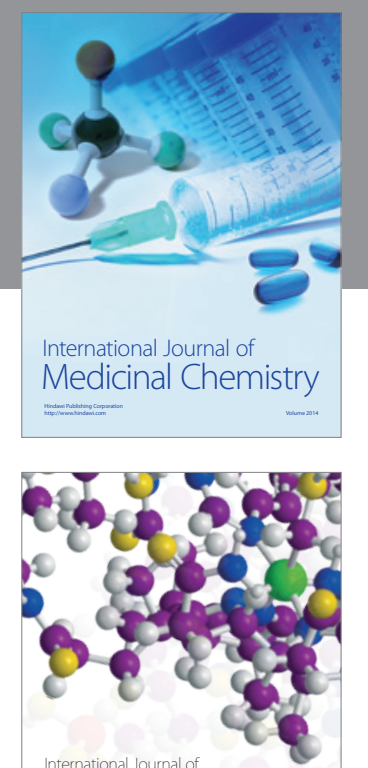

\section{Carbohydrate} Chemistry

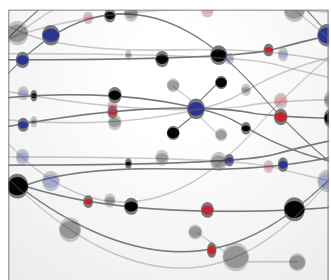

The Scientific World Journal
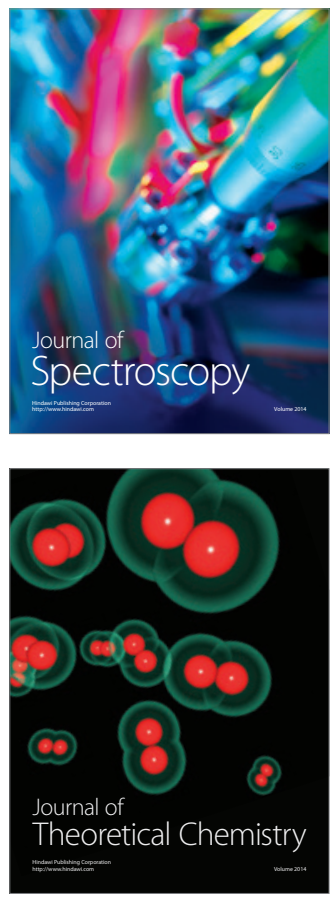
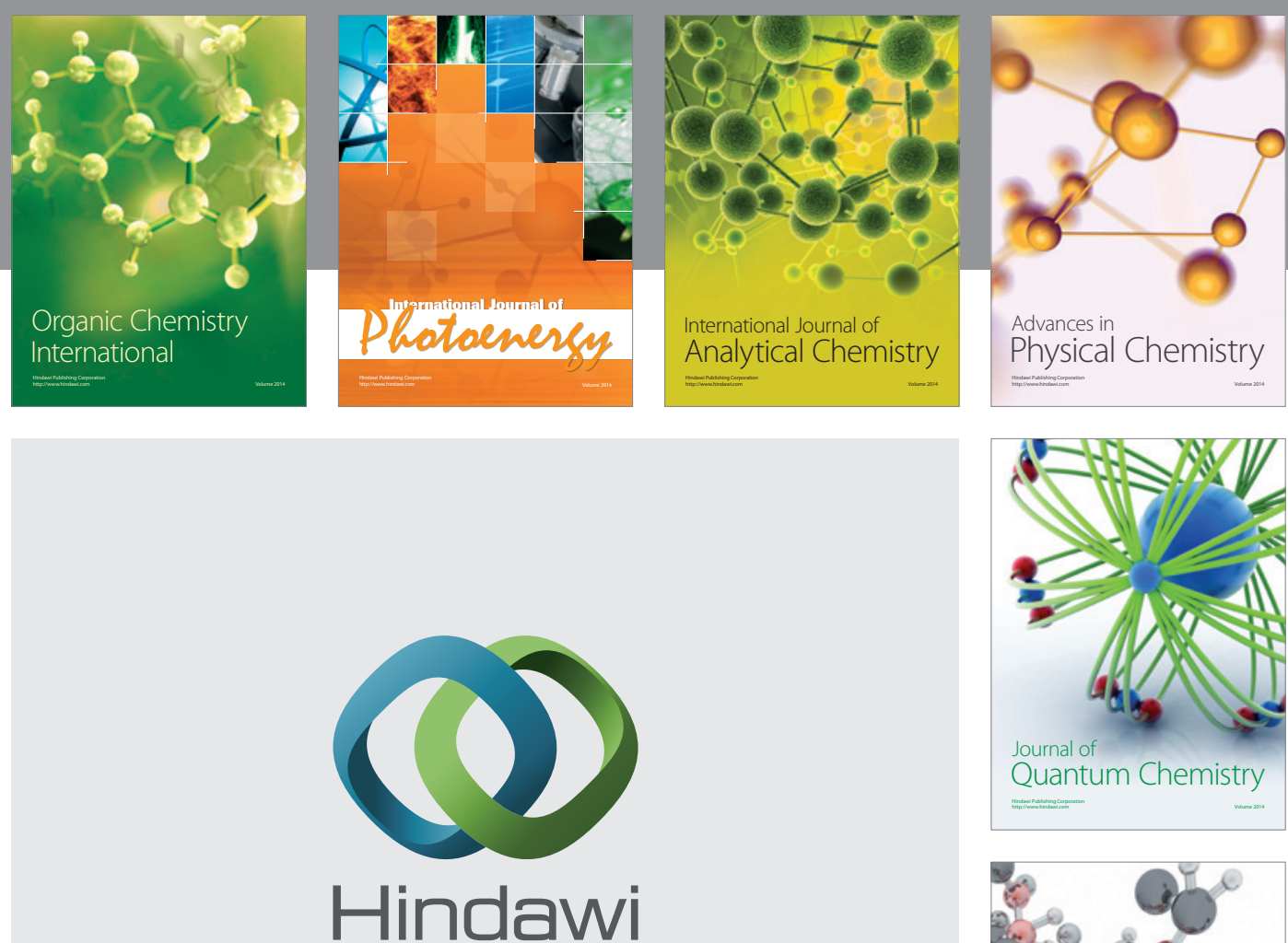

Submit your manuscripts at

http://www.hindawi.com

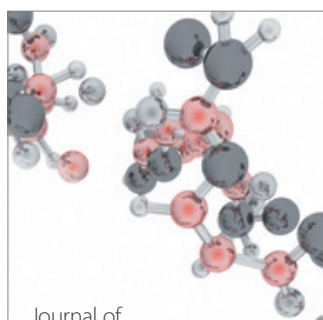

Analytical Methods

in Chemistry

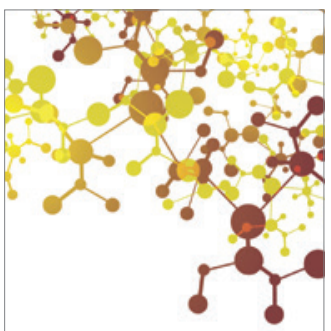

Journal of

Applied Chemistry

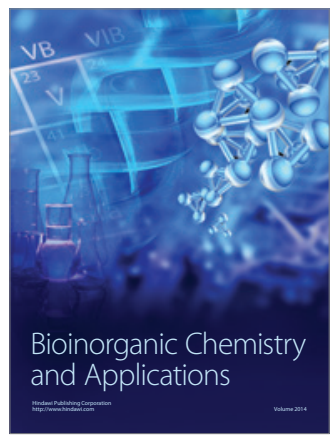

Inorganic Chemistry
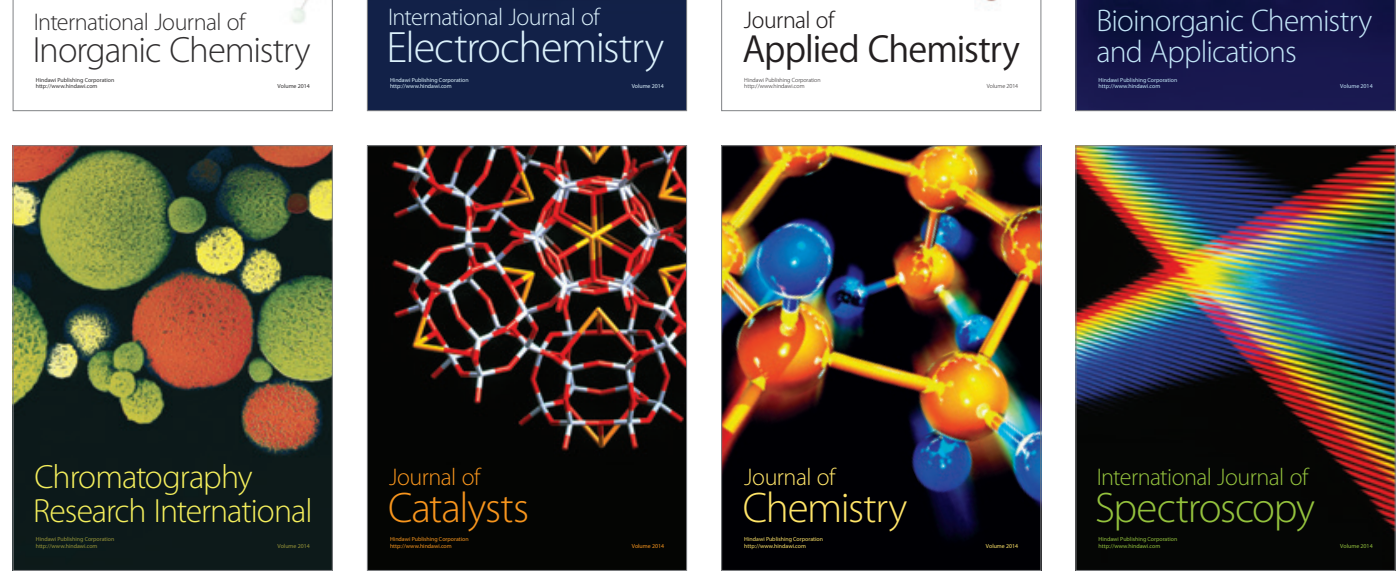